\title{
Convective Transport Theory for Surface Fluxes Tested over the Western Pacific Warm Pool
}

\author{
LAWRENCE GREISCHAR \\ Department of Atmospheric and Oceanic Sciences, University of Wisconsin-Madison, Madison, Wisconsin \\ ROLAND STULL \\ Atmospheric Science Programme, Department of Geography, University of British Columbia, \\ Vancouver, British Columbia, Canada
}

(Manuscript received 21 July 1997, in final form 9 July 1998)

\begin{abstract}
Turbulent flux measurements from five flights of the National Center for Atmospheric Research Electra aircraft during the Tropical Oceans and Global Atmosphere Coupled Ocean-Atmosphere Response Experiment (TOGA COARE) are used to test convective transport theory (CTT) for a marine boundary layer. Flights during light to moderate winds and under the clearest sky conditions available were chosen. Fluxes of heat, moisture, and momentum were observed by the eddy-correlation method. Mean kinematic values for the observed sensible and latent heat fluxes and momentum flux were $0.0061 \mathrm{~K} \mathrm{~m} \mathrm{~s}^{-1}, 0.0313 \mathrm{~g} \mathrm{~kg}^{-1} \mathrm{~m} \mathrm{~s}^{-1}$, and $0.0195 \mathrm{~m}^{2} \mathrm{~s}^{-2}$, respectively.

For the range of mixed-layer wind speeds $\left(0.8-8.4 \mathrm{~m} \mathrm{~s}^{-1}\right)$ studied here, the version of CTT that includes the mixed effects of buoyant and shear-driven transport give a better fit to the observations than either the COARE bulk algorithm or the pure free-convection version of CTT. This is to be expected because both of those latter parameterizations were designed for light winds $\left(<5 \mathrm{~m} \mathrm{~s}^{-1}\right.$ approximately).

The CTT empirical coefficients listed in Table 3 exhibited slight sensitivity to the COARE light flux conditions, compared to their previous estimates during larger fluxes over land. For example, COARE heat fluxes were roughly 10 times smaller than previous land-based flux measurements used to calculate CTT coefficients, but the corresponding empirical mixed-layer transport coefficients were only $3 \%$ smaller. COARE momentum fluxes were also roughly 10 times smaller, but the CTT coefficients were about four times smaller. The greater variation in momentum coefficient may be due, in part, to insufficient flight-leg length used to compute momentum fluxes, to uncertainties in the effects of the ocean surface current and waves, or perhaps to roughness differences.
\end{abstract}

\section{Introduction}

The western Pacific warm pool was identified during the Tropical Oceans and Global Atmosphere (TOGA) program as an important contributor to global climate variability. A Coupled Ocean-Atmosphere Response Experiment (COARE) was therefore designed, which included measurement of interfacial fluxes as one of the key elements. Webster and Lukas (1992) emphasized the importance of flux parameterizations especially for low-wind regimes.

The convective transport theory (CTT) proposed by Stull (1994) is just such a parameterization. This theory parameterizes surface fluxes of heat, moisture, and momentum as the product of an empirical transport coef-

Corresponding author address: Prof. Roland Stull, Atmospheric Science Programme, Department of Geography, 1984 West Mall, University of British Columbia, Vancouver, BC V6T 1Z2, Canada. E-mail: rstull@geog.ubc.ca ficient, a "buoyancy velocity scale," and the difference between mean surface and interior of mixed-layer values of the respective property.

The COARE observations made within the intensive flux array (IFA) in conjunction with extensive surface measurements by ships and buoys contain the information necessary to test CTT under marine conditions. Thirty-two flights of the National Center for Atmospheric Research (NCAR) Electra aircraft were made during the intensive operations period (IOP) of November 1992 and February 1993, many of which had lowlevel boundary layer legs in the area of concurrent surface measurements made by ships and at the improved meteorological instrumentation (IMET) buoy at $1^{\circ} 45^{\prime} \mathrm{S}$, $156^{\circ} \mathrm{E}$.

The published values of the empirical transport coefficients for CTT were originally estimated using airborne flux measurements from the Boundary Layer Field Experiment 1983 (BLX83) in Oklahoma (roughness length: $0.05 \mathrm{~m}$; latitude: $35^{\circ} \mathrm{N}$; vegetation: mixed 
pasture and crops; season: boreal spring). Data from another land-based experiment (Koorin) conducted under somewhat different conditions in Australia (roughness length: $0.4 \mathrm{~m}$; latitude: $16^{\circ} \mathrm{S}$; vegetation: uniform sparse trees; season: austral winter) were used to confirm the theory and the values of the coefficients.

The objective of this paper is to test this theory and its limits under the marine conditions of the western Pacific warm pool (roughness length: $3 \times 10^{-5} \mathrm{~m}$; latitude: $2^{\circ} \mathrm{S}$; marine conditions; season: austral summer) using the Electra aircraft data obtained during the COARE IOP. An overview of CTT is given in section 2. The Electra aircraft data and ancillary observations are described in section 3. Section 4 describes the data processing steps, and CTT is tested against the Electra data in section 5. Concluding remarks are made in section 6 .

\section{Model description}

During conditions of free convection and calm or light winds, turbulence is generated by buoyant thermals, rather than mechanically by surface-layer wind shear (Stull 1997). Convective thermals efficiently transport heat, moisture, and momentum between the surface and the mid-mixed layer, with a rate of vertical transport proportional to the Deardorff velocity $w_{*}=$ $\left[\left(g / \bar{T}_{v}\right) z_{i} \bar{w}^{\prime} \theta_{v s}^{\prime}\right]^{1 / 3}$, where $g$ is gravitational acceleration, $\overline{T_{v}}$ is the mean absolute virtual temperature, $z_{i}$ is the mixed-layer (ML) depth, and $\overline{w^{\prime} \theta_{v s}^{\prime}}$ is the surface kinematic vertical flux of virtual potential temperature, which is proportional to a buoyancy flux. While traditional drag laws fail in the limit of zero mean wind, surface fluxes during free convection nonetheless can be described by CTT (Stull 1994) over a range of calm to light winds:

$$
\begin{aligned}
u_{*}^{2} & =C_{* D} w_{*} M_{\mathrm{ML}} \\
\overline{w^{\prime} \theta_{s}^{\prime}} & =C_{* H} w_{*} \Delta \theta \\
\overline{w^{\prime} r_{s}^{\prime}} & =C_{* E} w_{*} \Delta r,
\end{aligned}
$$

where $u_{*}^{2}, \overline{w^{\prime} \theta_{s}^{\prime}}$, and $\overline{w^{\prime} r_{s}^{\prime}}$, are the surface kinematic fluxes of momentum, heat, and water vapor, respectively, and $u_{*}$ is also known as the friction velocity. The last factor in each equation above is a difference between the surface skin condition and the mid-mixedlayer value: $\Delta \theta=\theta_{\text {skin }}-\theta_{\mathrm{ML}}, \Delta r=r_{\text {skin }}-r_{\mathrm{ML}}$, and $\Delta M=M_{\mathrm{ML}}-M_{\text {skin }}=M_{\mathrm{ML}}$, where $M_{\text {skin }}=0$ by definition. By using skin and mid-mixed-layer values in the above formulations, it was proposed by Stull (1994) that the CTT parameterization should be independent of surface aerodynamic roughness length $z_{o}$. This assumption will be tested here.

The empirical mixed-layer transport coefficients for momentum, moisture, and heat were found (Stull 1994) to be $C_{* D}=0.023 \pm 0.007$ and $C_{* E} \approx C_{* H}=0.0063$ \pm 0.0016 , respectively, based on measurements over land (United States and Australia), where the error tolerance is given as a standard deviation. Stull had insufficient data to calculate $C_{* E}$ but hypothesized that it might be equal to $C_{*_{H}}$. We will test that hypothesis here. Kustas et al. (1996) has demonstrated that surfaces with complex geometry, such as forests, require corrections to the above coefficients to compensate for shading related to solar illumination versus viewing angles. Equations (1)-(3) are in implicit form, because the fluxes on the left side of Eqs. (2) and (3) depend on $w_{*}$, which itself is a function of heat and moisture fluxes via $\overline{w^{\prime} \theta_{v s}^{\prime}} \approx \overline{w^{\prime} \theta_{s}^{\prime}}(1+0.61 r)+0.61 \overline{\theta w^{\prime} r_{s}^{\prime}}$.

However, (1)-(3) can be rearranged into explicit form (Stull 1994):

$$
\begin{aligned}
u_{*}^{2} & =b_{D} w_{B} M_{\mathrm{ML}} \\
\overline{w^{\prime} \theta_{s}^{\prime}} & =b_{H} w_{B} \Delta \theta \\
\overline{w^{\prime} r_{s}^{\prime}} & =b_{E} w_{B} \Delta r,
\end{aligned}
$$

where convective transport coefficients $\left(b_{D}, b_{H}, b_{E}\right)$ are related to the mixed-layer coefficients by $b_{D}=$ $C_{* D} C_{* H}^{1 / 2}, b_{H}=C_{* H}^{3 / 2}$, and $b_{E}=C_{* E} C_{* H}^{1 / 2}$. The buoyancy velocity scale is

$$
w_{B} \equiv\left(\frac{g}{T_{v}} z_{i} \Delta \theta_{B}\right)^{1 / 2} .
$$

The buoyancy temperature difference is $\Delta \theta_{B} \equiv \beta \Delta \theta$, for $\beta \equiv \overline{w^{\prime} \theta_{v s}^{\prime}} / \overline{w^{\prime} \theta_{s}^{\prime}}$, which can be approximated in explicit form as

$$
\Delta \theta_{B} \approx \Delta \theta\left(1+0.61 r_{s}\right)+0.61 \theta_{s} \Delta r .
$$

For convection over land (Oklahoma and Australia) it was shown (Stull 1994) both theoretically and empirically that

$$
\Delta \theta_{B} \approx \Delta \theta_{v},
$$

where $\Delta \theta_{v}$ equals the difference of virtual potential temperatures between the surface skin and middle mixed layer. Equation (9) will be tested here for a maritime tropical atmosphere. This buoyancy velocity can also be used to parameterize the surface flux of virtual potential temperature:

$$
\overline{w^{\prime} \theta_{v s}^{\prime}}=b_{H} w_{B} \Delta \theta_{B} .
$$

A mixed-layer Richardson number was defined as

$$
R_{*} \equiv\left[w_{B} / M_{\mathrm{ML}}\right]^{2},
$$

where Stull (1994) suggested that even in noncalm conditions, turbulence is in quasi-free convection whenever $R_{*}>3$. This free convection condition will also be examined here for tropical maritime boundary layers.

Another prediction of CTT is that a diagnostic expression for mixed-layer depth is possible:

$$
z_{i}=\frac{1}{\left(g / T_{v}\right) \Delta \theta_{B}}\left(\overline{\frac{w^{\prime} \theta_{s}^{\prime}}{b_{H} \Delta \theta}}\right)^{2} .
$$

This, too, will be tested. 
TABLE 1. Boundary layer and surface-flux data from five flights of the NCAR Electra aircraft during the TOGA COARE IOP. Variables include start time (Local $=\mathrm{UTC}+11 \mathrm{~h}$ ) of beginning of the approximately 15-min low-level horizontal flight leg; flight ID, flight identification of Electra aircraft; leg ID, identification for each near-surface horizontal flight leg; $z$ leg, mean altitude of the flight leg above sea level; $z_{i}$; depth of mixed layer; $M_{\mathrm{ML}}, \theta_{\mathrm{ML}}$, and $r_{\mathrm{ML}}$, wind speed, mean potential temperature (relative to $100 \mathrm{kPa}$ ), and mixing ratio in the interior of the mixed layer; $P_{\text {surf }}, T_{\mathrm{skin}}$, and $\theta_{\mathrm{skin}}$, surface pressure, temperature, and potential temperature (relative to $100 \mathrm{kPa}$ ) of the surface radiometric skin temperature; $r_{\text {sat }}\left(T_{\text {skin }}\right)$, saturated mixing ratio at the surface skin temperature; $\Delta \theta=\theta_{\text {skin }}-\theta_{\mathrm{ML}} ; \Delta r=r_{\text {sat }}\left(T_{\text {skin }}\right)-r_{\mathrm{ML}} ;$ Here, $\left\langle w^{\prime} \theta_{s}^{\prime}\right\rangle$, $\left\langle w^{\prime} \theta_{v s}^{\prime}\right\rangle,\left\langle w^{\prime} r_{s}^{\prime}\right\rangle$, and $u^{* 2}$ are the leg-averaged surface kinematic vertical fluxes of heat, virtual temperature, moisture, and momentum, respectively. Means and standard deviations of all numbers in each column are shown at the bottom. Symbol t represents $\theta$.

\begin{tabular}{|c|c|c|c|c|c|c|c|c|c|c|c|c|c|c|c|c|c|c|}
\hline Electra & \multicolumn{4}{|c|}{ Flight Information } & \multicolumn{4}{|c|}{ Mixed Layer Variables } & \multicolumn{6}{|c|}{ Surface Variables } & \multicolumn{4}{|c|}{ Surface Kinematic Fluxes } \\
\hline Date & $\begin{array}{l}\text { Start } \\
\text { Time } \\
\text { (Local) } \\
\end{array}$ & $\begin{array}{l}\text { Flight } \\
\text { ID }\end{array}$ & $\begin{array}{c}\text { Leg } \\
10\end{array}$ & $\begin{array}{c}z \text { leg } \\
\text { asl } \\
(\mathrm{m})\end{array}$ & $\begin{array}{l}Z_{i} \\
(m) \\
\end{array}$ & $\begin{array}{r}\mathrm{M}_{\mathrm{ML}} \\
\left(\mathrm{ms}^{-1}\right) \\
\end{array}$ & $\begin{array}{l}\Theta_{\mathrm{ML}} \\
\left({ }^{\circ} \mathrm{K}\right) \\
\end{array}$ & $\begin{array}{c}r_{\mathrm{ML}} \\
\left(\mathrm{gkg}^{-1}\right) \\
\end{array}$ & $\begin{array}{l}P_{\text {surf }} \\
(\mathrm{mb}) \\
\end{array}$ & $\begin{array}{l}\mathrm{T}_{\text {skin }} \\
\left({ }^{\circ} \mathrm{C}\right)\end{array}$ & $\begin{array}{r}\Theta_{\text {skin }} \\
\left({ }^{\circ} \mathrm{K}\right) \\
\end{array}$ & $\begin{array}{l}r \text { (sat) } \\
\left(\mathrm{gkg}^{-1}\right) \\
\end{array}$ & $\begin{array}{l}\Delta \Theta \\
\left({ }^{\circ} \mathrm{K}\right) \\
\end{array}$ & $\begin{array}{c}\Delta \mathrm{r} \\
\left(\mathrm{gkg}^{-1}\right) \\
\end{array}$ & $\begin{array}{c}\mathrm{w}^{\prime} \mathrm{t}_{\mathrm{s}}^{\prime} \\
\left({ }^{\circ} \mathrm{Kms}^{-t}\right)\end{array}$ & $\begin{array}{l}w^{\prime} t_{v s s}^{\prime} \\
\left({ }^{\circ} \mathrm{Kms}^{-1}\right)\end{array}$ & $\begin{array}{c}\mathrm{w}^{\prime} \mathrm{r}_{\mathrm{s}}^{\prime} \\
\left(\mathrm{gkg}^{-1} \mathrm{~ms}^{-1}\right)\end{array}$ & $\begin{array}{c}u_{*}^{2} \\
\left(m^{2} s^{-2}\right)\end{array}$ \\
\hline \multirow[t]{5}{*}{ 28-Nov-92 } & $14: 52$ & RF04 & 1 & 66 & 720 & 2.2 & 301.3 & 18.0 & 1013.4 & 30.8 & 302.8 & 28.0 & 1.5 & 10.0 & 0.0054 & 0.0098 & 0.0235 & 0.0051 \\
\hline & $15: 11$ & & 2 & 36 & 720 & 1.9 & 301.3 & 17.9 & 1013.4 & 30.8 & 302.8 & 27.9 & 1.5 & 10.0 & 0.0048 & 0.0095 & 0.0250 & 0.0050 \\
\hline & $15: 28$ & & 3 & 38 & 720 & 2.2 & 301.4 & 17.8 & 1013.4 & 30.7 & 302.7 & 27.8 & 1.4 & 10.0 & 0.0047 & 0.0092 & 0.0238 & 0.0073 \\
\hline & $15: 46$ & & 4 & 38 & 720 & 1.8 & 301.4 & 17.9 & 1013.4 & 30.7 & 302.7 & 27.8 & 1.3 & 9.9 & 0.0055 & 0.0103 & 0.0255 & 0.0016 \\
\hline & 16:17 & & 5 & 34 & 720 & 1.6 & 301.4 & 17.6 & $10+3.3$ & 30.6 & 302.6 & 27.6 & 1.2 & 10.0 & 0.0047 & 0.0088 & 0.0217 & 0.0051 \\
\hline \multirow[t]{2}{*}{ 3-Dec-92 } & $06: 21$ & RF05 & 1 & 36 & 470 & 0.8 & 301.2 & 18.6 & 1011.4 & 30.2 & 302.4 & 27.0 & 1.2 & 8.4 & 0.0022 & 0.0055 & 0.0178 & 0.0021 \\
\hline & 08:21 & & 2 & 36 & 470 & 1.3 & 301.1 & 18.5 & 1012.5 & 30.4 & 302.5 & 27.4 & 1.4 & 8.8 & 0.0022 & 0.0048 & 0.0137 & 0.0016 \\
\hline \multirow[t]{2}{*}{ 4-Dec-92 } & $6: 07$ & RF06 & 1 & 32 & 680 & 0.9 & 301.3 & 18.5 & 1010.6 & 30.3 & 302.6 & 27.2 & 1.2 & 8.7 & 0.0016 & 0.0037 & 0.0116 & 0.0027 \\
\hline & $7: 55$ & & 2 & 34 & 630 & 1.3 & 301.2 & 18.3 & 1011.7 & 30.2 & 302.4 & 27.1 & 1.2 & 8.8 & 0.0021 & 0.0050 & 0.0157 & 0.0054 \\
\hline \multirow[t]{20}{*}{ 17-Dec-92 } & $13: 17$ & RF16 & $1 \mathrm{~A}$ & 37 & 390 & 4.3 & 300.6 & 19.0 & 1012.5 & 30.6 & 302.7 & 27.7 & 2.2 & 8.6 & 0.0066 & 0.0128 & 0.0329 & 0.0310 \\
\hline & & & $1 \mathrm{~B}$ & 39 & 332 & 5.5 & 300.6 & 18.7 & 1012.5 & 30.5 & 302.6 & 27.4 & 1.9 & 8.7 & 0.0069 & 0.0135 & 0.0354 & 0.0325 \\
\hline & & & $1 C$ & 40 & 275 & 8.4 & 299.7 & 18.7 & 1012.5 & 30.1 & 302.2 & 26.9 & 2.5 & 8.2 & 0.0142 & 0.0221 & 0.0420 & 0.0481 \\
\hline & $13: 38$ & & $2 A$ & 35 & 312 & 5.6 & 300.1 & 19.2 & 1012.5 & 30.2 & 302.3 & 27.0 & 2.2 & 7.8 & 0.0082 & 0.0139 & 0.0306 & 0.0318 \\
\hline & & & $2 \mathrm{~B}$ & 35 & 436 & 5.4 & 300.2 & 19.1 & 1012.5 & 30.2 & 302.3 & 27.0 & 2.1 & 7.8 & 0.0081 & 0.0134 & 0.0283 & 0.0298 \\
\hline & & & $2 C$ & 38 & 560 & 7.1 & 300.8 & 18.8 & 1012.5 & 30.3 & 302.4 & 27.1 & 1.5 & 8.3 & 0.0071 & 0.0154 & 0.0444 & 0.0352 \\
\hline & $13: 58$ & & $3 \mathrm{~A}$ & 35 & 630 & 5.7 & 300.3 & 19.0 & 1012.5 & 30.1 & 302.2 & 26.8 & 1.9 & 7.8 & 0.0092 & 0.0174 & 0.0442 & 0.0382 \\
\hline & & & 3B & 38 & 520 & 5.2 & 300.1 & 18.5 & 1012.5 & 29.9 & 302.0 & 26.6 & 1.9 & 8.1 & 0.0091 & 0.0173 & 0.0437 & 0.0311 \\
\hline & & & $3 C$ & 40 & 410 & 5.3 & 300.1 & 18.6 & 1012.5 & 30.0 & 302.0 & 26.6 & 2.0 & 8.0 & 0.0087 & 0.0165 & 0.0419 & 0.0414 \\
\hline & $14: 17$ & & $4 \mathrm{~A}$ & 36 & 445 & 6.0 & 300,8 & 19.2 & 1012.5 & 29.9 & 302.0 & 26.5 & 1.2 & 7.2 & 0.0080 & 0.0153 & 0.0392 & 0.0304 \\
\hline & & & 4B & 35 & 515 & 5.9 & 300.7 & 19.1 & 1012.5 & 29.8 & 301.8 & 26.3 & 1.2 & 7.2 & 0.0067 & 0.0143 & 0.0408 & 0.0233 \\
\hline & & & $4 \mathrm{C}$ & 37 & 585 & 6.2 & 300.7 & 19.3 & 1012.5 & 29.7 & 301.8 & 26.3 & 1.1 & 6.9 & 0.0067 & 0.0143 & 0.0408 & 0.0195 \\
\hline & $14: 37$ & & $5 \mathrm{~A}$ & 36 & 530 & 5.4 & 301.1 & 19.1 & 1012.5 & 30.3 & 302.4 & 27.1 & 1.3 & 8.0 & 0.0063 & 0.0121 & 0.0312 & 0.0266 \\
\hline & & & $5 \mathrm{~B}$ & 38 & 502 & 4.7 & 301.0 & 19.2 & 1012.5 & 30.3 & 302.3 & 27.1 & 1.3 & 7.9 & 0.0066 & 0.0141 & 0.0407 & 0.0154 \\
\hline & & & $5 \mathrm{C}$ & 39 & 475 & 4.2 & 301.2 & 19.0 & 1012.5 & 30.2 & 302.3 & 26.9 & 1.1 & 8.0 & 0.0047 & 0.0104 & 0.0305 & 0.0161 \\
\hline & $14: 55$ & & $6 \mathrm{~A}$ & 38 & 645 & 4.5 & 301.3 & 18.8 & 1012.5 & 30.1 & 302.2 & 26.8 & 0.9 & 8.1 & 0.0046 & 0.0112 & 0.0354 & 0.0202 \\
\hline & & & $6 B$ & 37 & 608 & 3.1 & 301.2 & 18.9 & 1012.5 & 30.1 & 302.2 & 26.9 & 1.0 & 8.0 & 0.0048 & 0.0099 & 0.0272 & 0.0062 \\
\hline & & & $6 C$ & 38 & 570 & 3.3 & 301.3 & 18.4 & 1012.5 & 30.1 & 302.2 & 26.9 & 0.9 & 8.5 & 0.0061 & 0.0118 & 0.0303 & 0.0141 \\
\hline & & & $6 D$ & 42 & 532 & 2.7 & 301.5 & 18.5 & 1012.5 & 30.3 & 302.4 & 27.2 & 0.9 & 8.6 & 0.0059 & 0.0122 & 0.0337 & 0.0096 \\
\hline & & & $6 \mathrm{E}$ & 42 & 495 & 1.2 & 301.5 & 18.9 & 1012.5 & 30.6 & 302.7 & 27.6 & 1.2 & 8.7 & 0.0059 & 0.0102 & 0.0228 & 0.0058 \\
\hline \multirow[t]{3}{*}{ 28-Jan-93 } & $12: 19$ & RF25 & 1 & 34 & 900 & 7.5 & 301.1 & 19.2 & 1011.7 & 30.3 & 302.5 & 27.2 & 1.4 & 8.0 & 0.0056 & 0.0142 & 0.0461 & 0.0439 \\
\hline & & Mean & & 38 & 551 & 4.0 & 300.9 & 18.7 & 1012.5 & 30.3 & 302.4 & 27.1 & 1.4 & 8.4 & 0.0061 & 0.0120 & 313 & 0.0195 \\
\hline & & SD & & 6 & 142 & 2.2 & 0. & 0.5 & 0.6 & 0.3 & 0.3 & 0.5 & 0.4 & 0.8 & 0.0025 & 0.0041 & 0.0099 & 0.0145 \\
\hline
\end{tabular}

Finally, for those conditions where mechanical generation of turbulence by wind shear is great enough to be comparable to convective turbulence, a "mixed" mechanical-buoyant version of CTT was also proposed:

$$
\begin{aligned}
u_{*}^{2} & =\left(C_{D \mathrm{ML}} M_{\mathrm{ML}}+b_{D \mathrm{ML}} w_{B}\right) M_{\mathrm{ML}} \\
\overline{w^{\prime} \theta_{s}^{\prime}} & =\left(C_{H \mathrm{ML}} M_{\mathrm{ML}}+b_{H \mathrm{ML}} w_{B}\right) \Delta \theta \\
\overline{w^{\prime} r_{s}^{\prime}} & =\left(C_{B \mathrm{ML}} M_{\mathrm{ML}}+b_{B \mathrm{ML}} w_{B}\right) \Delta r,
\end{aligned}
$$

where Stull (1994) empirically found the drag coefficient values for momentum and heat to be $C_{D M L}=$ 0.0035 and $C_{H \mathrm{ML}}=0.001$, respectively, with the convective transport coefficients for this mixed-convection case of $b_{D \mathrm{ML}}=0.0007$ and $b_{H \mathrm{ML}}=0.00025$, respectively.

Based on (7), (11), and (14), the buoyancy velocity and Deardorff velocity scales are related by

$$
w_{*}=\left(b_{H \mathrm{ML}}+C_{H \mathrm{ML}} R_{*}^{-1 / 2}\right)^{1 / 3} w_{B},
$$

which will be tested here.

\section{Observations}

Thirty low-level flight segments (Table 1) from five flights of the Electra aircraft flown during the COARE IOP, between November 1992 and February 1993, were used in this study to estimate surface fluxes of heat, 
moisture, and momentum. These data also provided estimates of the surface and middle boundary layer parameters needed to test the theory. The flight segments were chosen to avoid precipitating conditions, gust-front boundaries, and to be as cloud free as possible. An attempt was made to use flight data over a variety of wind speeds in order to test the CTT over a range from near-calm free-convective conditions to conditions in which mechanically generated turbulence transport associated with mean wind shear contributes significantly to the still-dominant buoyant transport. Surface data from the IMET buoy (Release 1.0b of WHOI buoy data from Dr. Robert Weller, Woods Hole Oceanographic Institute) were useful for choosing appropriate flight days as were satellite and radar images and surface and upperair analyses (TCIPO 1993; Asencio et al. 1993; Bond and Alexander 1994). A corrected version of the Electra's radiometric surface temperatures was obtained (Y. Serra 1997, personal communication). COARE shipbased current data obtained from the archive at the University of Hawaii were used to estimate the effects of surface currents on the model.

Flight conditions varied from clear with light winds to partly cloudy with winds up to $8 \mathrm{~m} \mathrm{~s}^{-1}$. Flights RF04, RF05, RF06, and RF25 were class 0 (described in the TOGA COARE Operations Plan as having clouds and very small, short-lived showers with areas less than 10 $\mathrm{km}^{2}$ covering not more than $5 \%$ of the flight area; TCIPO 1992) and flight RF16 was class 1 (indication of convective cores less than $25 \mathrm{~km}^{2}$ and lasting less than $30 \mathrm{~min}$ and no mesoscale organization greater than 50 $\mathrm{km}$ or long-lived stratiform rain areas greater than 2500 $\mathrm{km}^{2}$ within the target domain). Rainfall data (15 min averages) from the R/V Franklin (Release 1.0 from Bradley and Coppin, CSIRO Centre for Environmental Mechanics, Canberra, Australia), which was in the vicinity of flights RF04, RF05, RF06, and RF25, indicated no precipitation at its location during these flights. Surface radar data were available for flights RF04 and RF16, which roughly delineated cloudy areas. Sensors on the Electra detected some liquid water content only during short sections of leg 2 of flight RF06. These sections were excluded from the analysis.

Fast-rate measurements of the global positioning system (GPS)-corrected wind components, potential temperature, and mixing ratio were used to compute the eddy-correlation surface fluxes of heat, moisture, and momentum. These variables are described in detail in Miller and Friesen (1989). Slow-rate measurements of aircraft position and time, surface skin temperature, and an estimate of surface pressure were used to map lowlevel flight legs and determine the pressure and temperature conditions at the surface. Estimates of mixedlayer properties were made where the aircraft descended to or ascended from low-altitude flight legs, resulting in several vertical profiles through the mixed layer during each day's flight pattern. Some flight patterns also had legs at higher levels within the mixed layer.

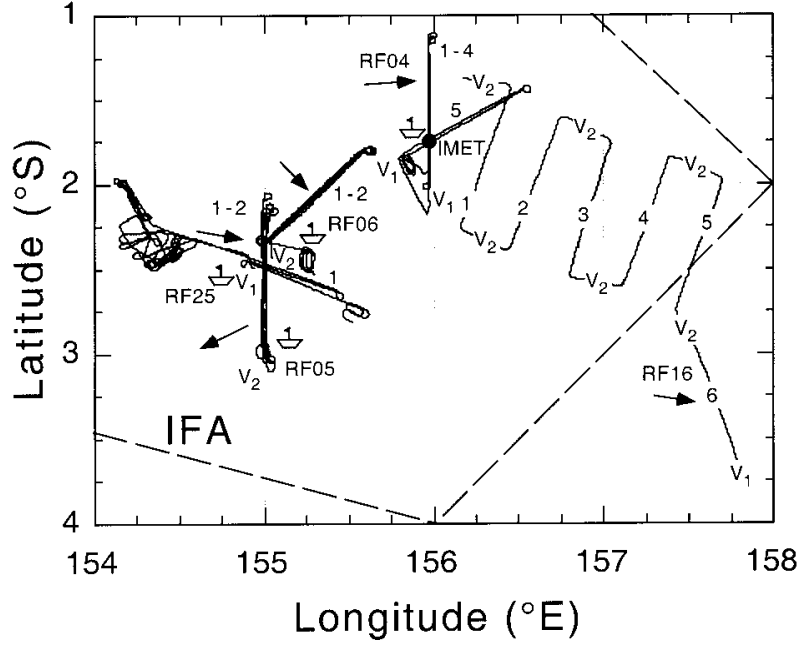

FIG. 1. Low-level flight paths show locations of flight legs and vertical profiles (slant ascent and descent flights, shown by letter $\mathrm{V}$ with subscript indicating number of profiles at each approximate location) used in this study. The position of the IMET buoy and the approximate locations of the ship R/V Franklin (ship symbol) during the times of flights RF04, RF05, RF06, and RF25 are shown. Approximate wind direction during each flight is indicated by an arrow near the flight label. The boundary of the IFA is indicated by a dashed line.

\section{Data processing}

Processing of the flight data began by producing twoand three-dimensional plots of the aircraft's flight path in order to identify suitable low-level flight legs. Figure 1 shows the locations of the low-level legs studied from the five separate flights. The IMET buoy is shown, as are the approximate locations of the R/V Franklin during flights RF04, RF05, RF06, and RF25. An elevation versus time plot of the on-station part of a flight was also used to define the start and finish times of each flight leg, and of the slant ascent or descent sounding that often occurred between the low-level flight legs.

Fast-rate values for the three wind components, mixing ratio, and potential temperature were extracted for each leg and plotted (as in Fig. 2). The following restrictions (Sun et al. 1996) were placed on the data: 1) differences of flight levels between adjacent sampling points were required to be less than $5 \mathrm{~m}$; and 2) roll and pitch angles were restricted to $-4^{\circ}$ to $+4^{\circ}$ and $0^{\circ}$ to $3^{\circ}$, respectively. Also as in Sun et al. (1996), points in the fast-rate data that differed by more than four standard deviations from the mean along $1 \mathrm{~km}$ of flight were replaced by using a linear interpolation between good data values. Fluxes calculated using this "despiked" data were mostly changed by less than $1 \%$ with a maximum difference of $5 \%$.

The fast rate data are sampled at $20 \mathrm{~Hz}$, which given an aircraft speed of approximately $100 \mathrm{~m} \mathrm{~s}^{-1}$ results in a short wavelength sampling limit of approximately 10 $\mathrm{m}$. In order to remove mesoscale effects of diameters larger than $2500 \mathrm{~m}$ and corresponding to wavelengths 

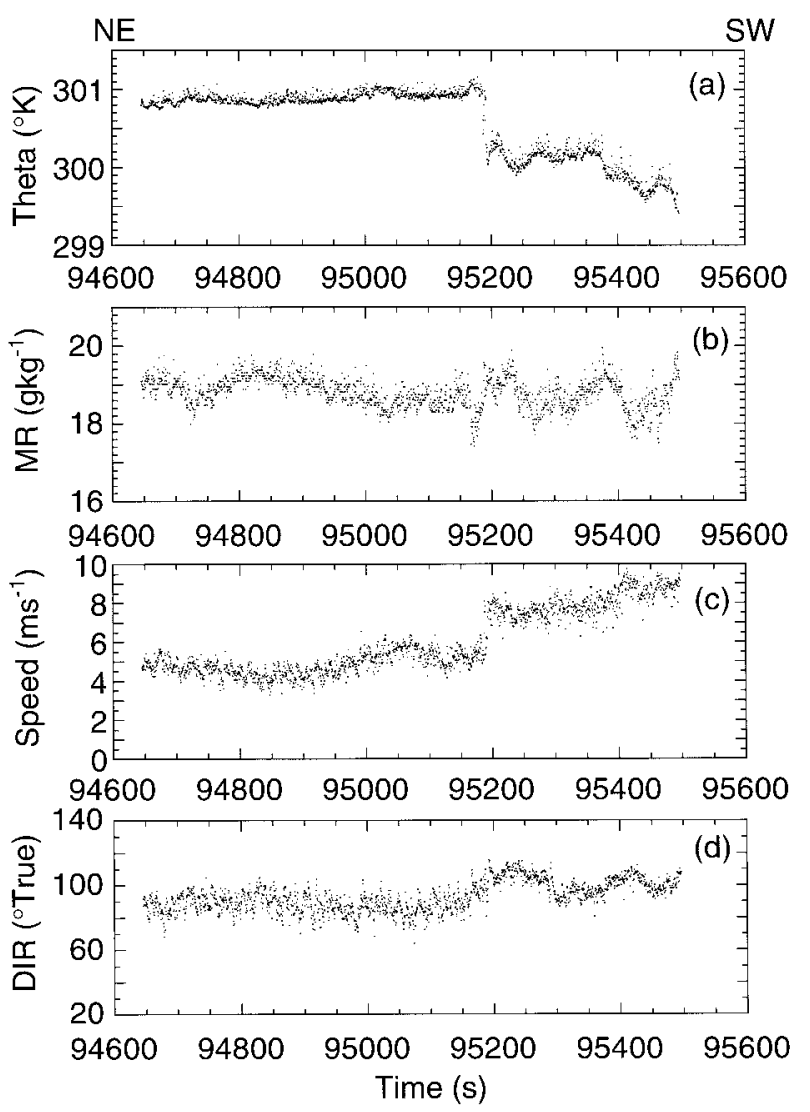

FIG. 2. Times series plots of (a) potential temperature, (b) mixing ratio, (c) wind speed, and (d) wind direction for leg 1 of flight RF16. Time (in s) from 0000 UTC on 16 December 1992. Every fifth point of the $20-\mathrm{Hz}$ data is plotted.

greater than $5 \mathrm{~km}$, a 50 -s moving linear average and trend was subtracted from the fast-rate data in a manner similar to Otles and Young (1996). Eddy fluxes of heat, moisture, and momentum were then computed from 18 $\mathrm{km}$ or longer sections of these filtered flight legs using a program that first removed any remaining trend.

Thicknesses of the mixed layer were estimated from vertical profiles of virtual potential temperature, mixing ratio, and winds measured during aircraft slant ascent and descent soundings at the ends of the low-level flight legs. One-second averages of the fast data were plotted in these vertical profiles. Radar altitudes were used up to their limit of about $750 \mathrm{~m}$, with pressure altitudes approximately adjusted to match the radar data, used above this level. Only one mixed-layer thickness estimate was greater than $750 \mathrm{~m}$ for the cases studied here. Generally, the vertical profile of virtual potential temperature gave the best indication of mixed-layer thickness, with a nearly constant value of $\theta_{v}$ up to the mixedlayer depth $z_{i}$. The locations of these slant soundings are shown in Fig. 1.

Surface values of temperature, pressure, and moisture were estimated as follows. A corrected version of the Electra radiometric surface temperatures (Y. Serra 1997, personal communication) includes corrections for emissivity, reflectivity, transient trends, and offset were averaged to obtain an initial estimate of $T_{\text {skin }}$. An approximate correction for absorption due to moisture content between the aircraft and surface was estimated from the rate of change of the radiometric surface temperature with height during slant ascent and descent soundings (Fig. 1). This rate appeared to be fairly linear over the lowest several hundred meters of elevation and varied from $+0.06 \mathrm{~K}$ to $+0.14 \mathrm{~K}$ per $100-\mathrm{m}$ decrease in elevation. A mean value of $+0.1 \mathrm{~K}$ per 100 $\mathrm{m}$ was used, resulting in corrections for this effect of less than $0.1 \mathrm{~K}$ for the $32-66-\mathrm{m}$ flight elevations. A rough comparison of these corrected sea surface temperatures with concurrent ship values from the R/V Franklin showed occasional agreement but with a tendency for the ship observations to be slightly cooler. If real, such a bias would tend to make the free-convective coefficients for heat and moisture somewhat larger. Surface pressure was obtained from a data channel that estimates the surface pressure from aircraft values of pressure, virtual temperature, and elevation. Since the aircraft potential temperatures were defined with respect to a reference pressure of $100 \mathrm{kPa}, T_{\text {skin }}$ was also converted to a potential temperature at this reference pressure using the surface pressure estimate. Saturation mixing ratio at the surface was obtained from $T_{\text {skin }}$ and surface pressure using Teten's formula (Stull 1988). As in Fairall et al. (1996) this saturation mixing ratio is multiplied by 0.98 to account for the reduction of vapor pressure caused by a typical salinity of 34 parts per thousand.

Mean mixed-layer values of wind speed, potential temperature, and mixing ratio were estimated from mean values at the flight elevation. The aircraft offset table from the TOGA COARE Flux Group (1996) was used to correct observational offsets of the Electra aircraft instrumentation. GPS-corrected winds (D. Raymond 1997, personal communication) were used to estimate wind speeds. Several pairs of collinear flight lines flown within approximately a $0.6-\mathrm{h}$ time period at different elevations from three of the flights showed that potential temperature and mixing ratio remained nearly constant between approximately 35- and 95-m elevation, although wind speed generally increased slightly with altitude. The vertical profiles used to estimate mixed-layer thicknesses also indicated fairly constant values of these parameters through the mixed layer.

Table 1 lists the observed surface values of temperature $T_{\text {skin }}$, potential temperature $\theta_{\text {skin }}$, pressure $P_{\text {surf }}$, and mixing ratio $r_{\text {sat }}$. Also listed are mixed-layer values of thickness $z_{i}$, wind speed $M_{\mathrm{ML}}$, potential temperature $\theta_{\mathrm{ML}}$, and mixing ratio $r_{\mathrm{ML}}$, determined for each flight-leg segment. Also in Table 1 are the surface fluxes of heat, moisture, and momentum. Surface fluxes of heat, moisture, and momentum were assumed to be reasonably represented by their respective values measured from 
TABLE 2. Mixed-layer and buoyancy scales. Variables are $\beta$, ratio of virtual temperature flux to heat flux, both at the surface; $\Delta \theta_{B}$, buoyancy temperature difference; $\Delta \theta_{v}$, virtual potential temperature difference between the surface skin and the mixed layer; $w^{*}$, Deardorff velocity; $w_{B}$, buoyancy velocity; $R^{*}$, mixed-layer Richardson number; $C{ }_{D}^{*}$, mixed-layer transport coefficient for momentum; $C^{*}{ }_{H}$, mixed-layer transport coefficient for heat; $C_{E}^{*}$, mixed-layer transport coefficient for moisture. Asterisks in the column labeled "Free conv." indicate those data for which $R^{*}>3.0$, which were used to calculate the boldface mean values at the bottom of the table. Convective transport coefficients for momentum, heat, and moisture are indicated by $b_{D}, b_{H}$, and $b_{E}$, respectively.

\begin{tabular}{|c|c|c|c|c|c|c|c|c|c|c|c|c|c|c|c|c|}
\hline $\begin{array}{l}\text { Electra } \\
\text { Date }\end{array}$ & $\begin{array}{l}\text { Start } \\
\text { Time } \\
\text { (Local) }\end{array}$ & $\begin{array}{l}\text { Flight } \\
\text { ID }\end{array}$ & $\begin{array}{c}\text { Leg } \\
\text { ID }\end{array}$ & $\beta$ & $\begin{array}{l}\Delta \Theta_{\mathrm{B}} \\
\left({ }^{\circ} \mathrm{K}\right)\end{array}$ & $\begin{array}{l}\Delta \Theta_{\mathrm{V}} \\
\left({ }^{\circ} \mathrm{K}\right)\end{array}$ & $\begin{array}{c}\mathrm{w} \\
\left(\mathrm{ms}^{-1}\right)\end{array}$ & $\begin{array}{l}\mathrm{w}_{B} \\
\left(\mathrm{~ms}^{-1}\right)\end{array}$ & $\mathrm{R}$ & $\begin{array}{c}\mathrm{C}_{* \mathrm{D}} \\
\text { Momen. }\end{array}$ & $\begin{array}{l}\mathrm{C}_{x_{H}} \\
\text { Heat }\end{array}$ & $\begin{array}{c}\mathrm{C}_{* E} \\
\text { Moist. }\end{array}$ & $\begin{array}{l}\text { Free } \\
\text { conv. }\end{array}$ & Momen. & Heat & Moist. \\
\hline \multirow[t]{5}{*}{ 28-Nov-92 } & $14: 52$ & RF04 & 1 & 1.81 & 2.7 & 3.4 & 0.61 & 8.0 & 13.1 & 0.0038 & 0.0059 & 0.0039 & * & 0.00029 & 0.00045 & 0.00029 \\
\hline & $15: 11$ & & 2 & 1.97 & 2.9 & 3.3 & 0.60 & 8.2 & 18.3 & 0.0043 & 0.0055 & 0.0041 & * & 0.00032 & 0.00040 & 0.00030 \\
\hline & $15: 28$ & & 3 & 1.94 & 2.6 & 3.2 & 0.59 & 7.9 & 13.4 & 0.0057 & 0.0058 & 0.0040 & * & 0.00043 & 0.00044 & 0.00030 \\
\hline & $15: 46$ & & 4 & 1.86 & 2.5 & 3.2 & 0.62 & 7.7 & 18.1 & 0.0014 & 0.0066 & 0.0042 & * & 0.00012 & 0.00054 & 0.00034 \\
\hline & $16: 17$ & & 6 & 1.85 & 2.2 & 3.0 & 0.59 & 7.1 & 18.9 & 0.0053 & 0.0069 & 0.0037 & * & 0.00044 & 0.00057 & 0.00031 \\
\hline \multirow[t]{2}{*}{ 3-Dec-92 } & $06: 21$ & RF05 & 1 & 2.49 & 3.0 & 2.8 & 0.44 & 6.8 & 70.0 & 0.0058 & 0.0042 & 0.0049 & * & 0.00037 & 0.00027 & 0.00031 \\
\hline & $08: 21$ & & 4 & 2.16 & 3.0 & 3.1 & 0.41 & 6.8 & 29.8 & 0.0030 & 0.0038 & 0.0037 & * & 0.00018 & 0.00023 & 0.00023 \\
\hline \multirow[t]{2}{*}{ 4-Dec-92 } & $6: 07$ & RF06 & 1 & 2.36 & 2.9 & 2.9 & 0.43 & 8.0 & 79.2 & 0.0070 & 0.0030 & 0.0031 & * & 0.00038 & 0.00016 & 0.00017 \\
\hline & 7:55 & & 4 & 2.42 & 2.8 & 2.8 & 0.46 & 7.6 & 36.5 & 0.0092 & 0.0038 & 0.0038 & * & 0.00056 & 0.00023 & 0.00023 \\
\hline \multirow[t]{20}{*}{ 17-Dec-92 } & 13:17 & RF16 & $1 \mathrm{~A}$ & 1.92 & 4.2 & 3.8 & 0.54 & 7.3 & 2.9 & 0.0134 & 0.0057 & 0.0070 & & 0.00099 & 0.00042 & 0.00052 \\
\hline & & & 1B & 1.95 & 3.8 & 3.6 & 0.52 & 6.4 & 1.4 & 0.0114 & 0.0068 & 0.0078 & & 0.00093 & 0.00055 & 0.00063 \\
\hline & & & $1 \mathrm{C}$ & 1.55 & 3.9 & 4.1 & 0.58 & 5.9 & 0.5 & 0.0099 & 0.0097 & 0.0088 & & 0.00096 & 0.00094 & 0.00086 \\
\hline & $13: 38$ & & $2 \mathrm{~A}$ & 1.70 & 3.7 & 3.6 & 0.52 & 6.1 & 1.2 & 0.0109 & 0.0073 & 0.0076 & & 0.00092 & 0.00061 & 0.00064 \\
\hline & & & 28 & 1.65 & 3.4 & 3.5 & 0.57 & 7.0 & 1.7 & 0.0097 & 0.0068 & 0.0063 & & 0.00079 & 0.00056 & 0.00052 \\
\hline & & & $2 \mathrm{C}$ & 2.15 & 3.3 & 3.1 & 0.65 & 7.7 & 1.2 & 0.0076 & 0.0072 & 0.0082 & & 0.00064 & 0.00061 & 0.00069 \\
\hline & $13: 58$ & & $3 \mathrm{~A}$ & 1.89 & 3.6 & 3.3 & 0.71 & 8.6 & 2.2 & 0.0095 & 0.0069 & 0.0081 & & 0.00078 & 0.00057 & 0.00066 \\
\hline & & & 3B & 1.89 & 3.6 & 3.4 & 0.66 & 7.9 & 2.3 & 0.0091 & 0.0072 & 0.0082 & & 0.00076 & 0.00061 & 0.00069 \\
\hline & & & $3 \mathrm{C}$ & 1.89 & 3.7 & 3.5 & 0.60 & 7.0 & 1.7 & 0.0129 & 0.0074 & 0.0087 & & 0.00110 & 0.00063 & 0.00074 \\
\hline & $14: 17$ & & $4 \mathrm{~A}$ & 1.91 & 2.3 & 2.5 & 0.60 & 5.7 & 0.9 & 0.0085 & 0.0112 & 0.0090 & & 0.00089 & 0.00118 & 0.00094 \\
\hline & & & $4 \mathrm{~B}$ & 2.12 & 2.5 & 2.5 & 0.62 & 6.5 & 1.2 & 0.0064 & 0.0092 & 0.0092 & & 0.00061 & 0.00088 & 0.00087 \\
\hline & & & $4 \mathrm{C}$ & 2.12 & 2.3 & 2.4 & 0.64 & 6.7 & 1.2 & 0.0049 & 0.0095 & 0.0091 & & 0.00047 & 0.00091 & 0.00088 \\
\hline & $14: 37$ & & $5 \mathrm{~A}$ & 1.93 & 2.5 & 2.8 & 0.59 & 6.5 & 1.5 & 0.0084 & 0.0083 & 0.0067 & & 0.00076 & 0.00075 & 0.00060 \\
\hline & & & $5 B$ & 2.15 & 2.8 & 2.8 & 0.61 & 6.8 & 2.1 & 0.0054 & 0.0082 & 0.0084 & & 0.00048 & 0.00074 & 0.00076 \\
\hline & & & $5 \mathrm{C}$ & 2.20 & 2.4 & 2.6 & 0.54 & 6.1 & 2.1 & 0.0071 & 0.0080 & 0.0071 & & 0.00063 & 0.00071 & 0.00063 \\
\hline & 14:55 & & $6 \mathrm{~A}$ & 2.41 & 2.1 & 2.4 & 0.61 & 6.6 & 2.2 & 0.0074 & 0.0089 & 0.0071 & & 0.00069 & 0.00083 & 0.00067 \\
\hline & & & $6 \mathrm{~B}$ & 2.05 & 2.0 & 2.5 & 0.58 & 6.3 & 4.2 & 0.0035 & 0.0086 & 0.0059 & * & 0.00032 & 0.00079 & 0.00054 \\
\hline & & & $6 \mathrm{C}$ & 1.92 & 1.7 & 2.5 & 0.60 & 5.7 & 3.0 & 0.0072 & 0.0113 & 0.0060 & & 0.00076 & 0.00119 & 0.00063 \\
\hline & & & $6 \mathrm{D}$ & 2.06 & 1.9 & 2.5 & 0.59 & 5.8 & 4.6 & 0.0060 & 0.0107 & 0.0066 & * & 0.00062 & 0.00110 & 0.00068 \\
\hline & & & $6 \mathrm{E}$ & 1.72 & 2.1 & 2.8 & 0.54 & 5.8 & 23.2 & 0.0089 & 0.0090 & 0.0048 & * & 0.00084 & 0.00084 & 0.00045 \\
\hline \multirow[t]{5}{*}{ 28-Jan-93 } & 12:19 & RF25 & 1 & 2.52 & 3.4 & 2.9 & 0.74 & 10.0 & 1.8 & 0.0079 & 0.0055 & 0.0078 & & 0.00058 & 0.00041 & 0.00058 \\
\hline & & & \multirow{2}{*}{\multicolumn{6}{|c|}{ For Free Convection Only: }} & Mean & 0.0053 & 0.0061 & 0.0044 & * & 0.00041 & 0.00050 & 0.00035 \\
\hline & & & & & & & & & SD & 0.0023 & 0.0024 & 0.0010 & * & 0.00020 & 0.00029 & 0.00014 \\
\hline & & Mean & & 2.02 & 2.9 & 3.0 & 0.58 & 7.0 & 12.0 & 0.0074 & 0.0073 & 0.0065 & $\mathrm{ALL}$ & 0.00062 & 0.00064 & 0.00056 \\
\hline & & SD & & 0.25 & 0.7 & 0.5 & 0.07 & 1.0 & 19.5 & 0.0029 & 0.0022 & 0.0020 & ALL & 0.00026 & 0.00027 & 0.00022 \\
\hline
\end{tabular}

the lowest aircraft flight level, because flux profile slopes were expected to be relatively small in the COARE region. The momentum flux components were combined to yield the square of the friction velocity $\left[u_{*}^{2}=\left(\overline{u^{\prime} w^{\prime}}+\overline{w^{\prime} w^{\prime}}\right)^{1 / 2}\right]$. The surface virtual temperature flux $\overline{w^{\prime} \theta_{v s}^{\prime}}$ was computed from the heat and moisture fluxes (Stull 1994), and this in turn was used to compute the Deardorff convective velocity $w_{*}=$ $\left[\left(g / T_{v}\right) z_{i} \overline{w^{\prime} \theta_{v s}^{\prime}}\right]^{1 / 3}$. Table 2 shows the following mixedlayer and buoyancy scales: ratio of kinematic virtual temperature flux to heat flux $\beta$; buoyancy temperature difference $\Delta \theta_{B}$ [Eq. (8)]; virtual temperature difference between the surface skin and the mixed layer $\Delta \theta_{v}$; buoyancy velocity scale $w_{B}$ [Eq. (7)]; mixed-layer Richardson number $R_{*}$ [Eq. (11)]; and the mixed-layer transport coefficients for momentum $C_{* D}$, heat $C_{* H}$, and moisture $C_{* E}$, and the corresponding convective transport coefficients $\left(b_{D}, b_{H}, b_{E}\right)$.

\section{Results}

Figure 2 shows the recorded potential temperature, mixing ratio, wind speed, and direction (vs time in seconds from 0000 UTC on 16 December 1992) for leg 1 


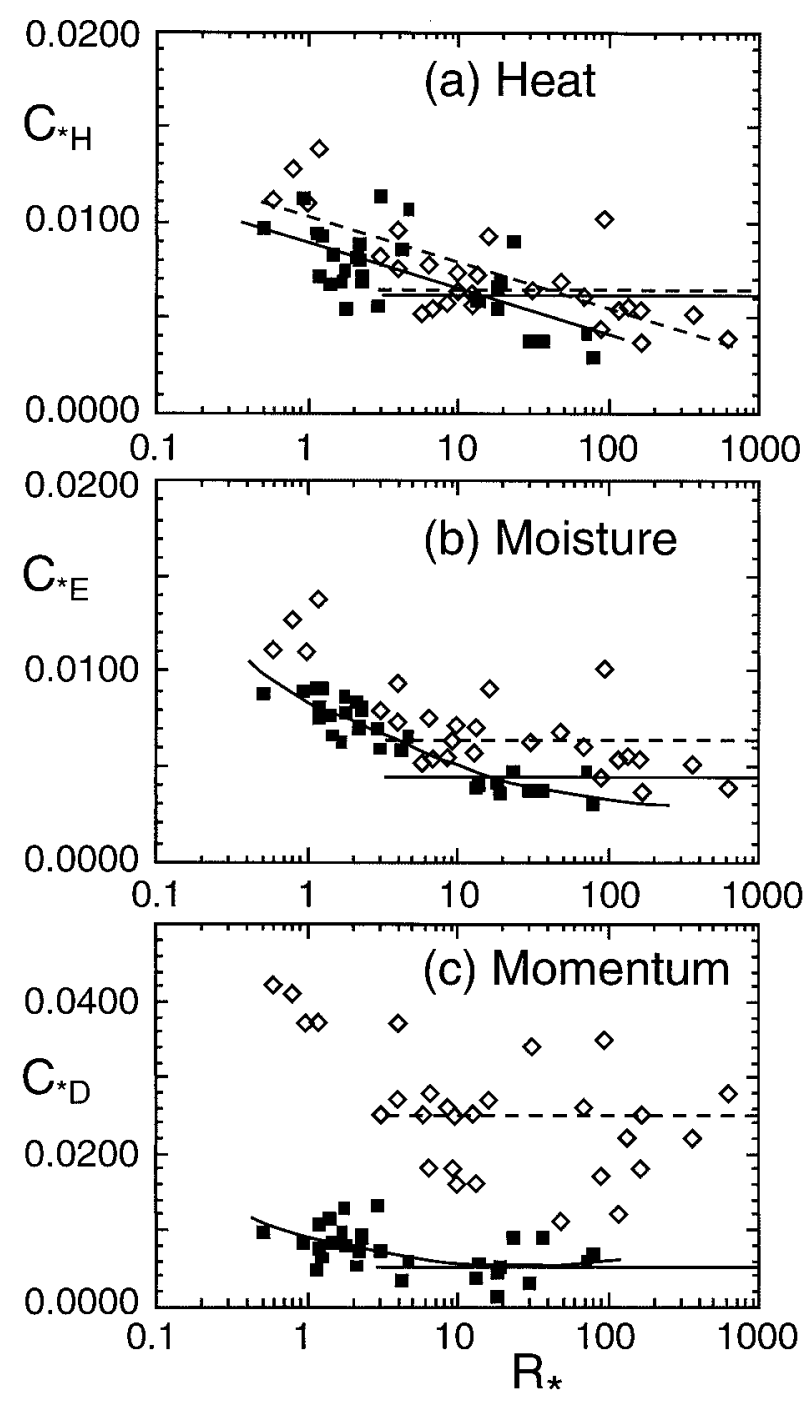

FIG. 3. Variation of mixed-layer transport coefficients for (a) heat $C_{* H}$, (b) moisture $C_{* E}$, and (c) momentum $C_{* D}$, with mixed-layer Richardson number $R_{*}$. Values for the 30 COARE flight segments studied are plotted as black squares, and for comparison the BLX83 land-based data are shown by diamonds. Approximate free convection occurs for $R_{*}>3.0$, as indicated by the relatively constant values of mixed-layer transport coefficients for moisture and momentum. Thin horizontal lines (dashed for BLX83) show mean values for the transport coefficients: $C_{* H}=0.0061(0.0063)$ and $C_{* E}=0.0044$ $(0.0063)$ for heat and moisture, respectively; and $C_{* D}^{* E}=0.0053$ (0.0230) for momentum. (a) Shows linear fits to the semilog graphs for the COARE data (solid) and BLX83 data (dashed). (b) and (c) Thicker curves show second-order polynomial fits [in terms of $\left.\log \left(R_{*}\right)\right]$ to the semilog graphs of the COARE data.

of flight RF16. A cool gust front similar to one seen in ship data (Tsukamoto and Ishida 1995) occurs near $95200 \mathrm{sec}$. It is very evident in the temperature and wind data, and appears as an increase in variance of the mixing ratio observations. The liquid water channel on the Electra aircraft did not indicate any precipitation during this flight leg. The flight segments evaluated from this leg were chosen to avoid the discontinuities at the boundary of the gust front. Table 1 shows the changes in fluxes associated with this event (between RF16 1A and $1 \mathrm{~B}$ on the warm side and $1 \mathrm{C}$ on the cool side). Consistent with the theory, heat, moisture, and momentum fluxes increased by approximately 100\%, 23\% and $50 \%$, respectively, with the cooling, drying, and increased winds of the mixed layer.

Figure 3 shows the variation of mixed-layer transport coefficients for heat, moisture, and momentum with the mixed-layer Richardson number. The land-based values from BLX83 are also plotted for comparison. As in Stull (1994) $R_{*}>3.0$ was the criterion adopted for free convection, indicating that buoyant production of turbulence kinetic energy is at least three times greater than shear production. As can be seen from both the BLX83 and the COARE data in Fig. 3, the choice of $R_{*}>3$ to define free convection is somewhat arbitrary, with the empirical coefficients becoming even more uniform as $R_{*}$ increases to 10 and beyond. Also plotted (Figs. $3 \mathrm{~b}$ and $3 \mathrm{c}$ ) are second-order polynomial fits [in terms of $\log \left(R_{*}\right)$ ], showing that the coefficients for moisture and momentum become approximately steady for free convection. The variation of $C_{* H}$ with $R_{*}$ shows a nearly linear variation (Fig. 3a) over the range of the semilog plot. This was also found over land (Stull 1994), which suggests that vertical heat transport continues to become more efficient as winds become lighter, perhaps caused by better organization of the coherent thermal structures. Figure $3 \mathrm{a}$ shows the remarkably similar linear trends for the COARE and BLX83 data with a fit to the combined datasets yielding the relation $C_{* H}=0.0091-$ $0.0020 \log \left(R_{*}\right)$.

Table 2 shows the results of averaging the 12 freeconvective cases for the proposed empirical values $C_{* D}$ $=0.0053( \pm 0.0023), C_{* H}$ (heat) $=0.0061( \pm 0.0024)$, and $C_{* E}$ (moisture) $=0.0044( \pm 0.0010)$. These values are plotted as horizontal solid lines in Fig. 3 and can be compared to the land-based BLX83 values (dashed lines). The very good agreement between the COARE and BLX83 values for $C_{* H}$ is evident in Fig. 3a. Figure $3 \mathrm{~b}$ also has plotted the BLX83 values of $C_{* H}$ in order to test Stull's (1994) assumption that $C_{* E} \approx C_{* H}$. Although $C_{* E}$ is smaller than the BLX83 (and COARE) values of $C_{* H}$, it is still within error limits. However, $C_{* D}$ (Fig. 3c) is only about $25 \%$ of the published value for nonmarine conditions. There is considerable scatter in the momentum data, which may have several causes. Some might be related to mesoscale heterogeneity caused by precipitation-induced intrusions of cool air masses (Williams et al. 1996). In addition, some may be due to insufficient leg length used to compute the momentum fluxes, to uncertainties in the mean mixedlayer wind speed and surface currents; but the difference is large enough to suggest that roughness-length effects or other factors may need to be incorporated into the CTT.

The free and mixed formulations of CTT were tested. Figure 4 shows plots of predicted versus observed fluxes 

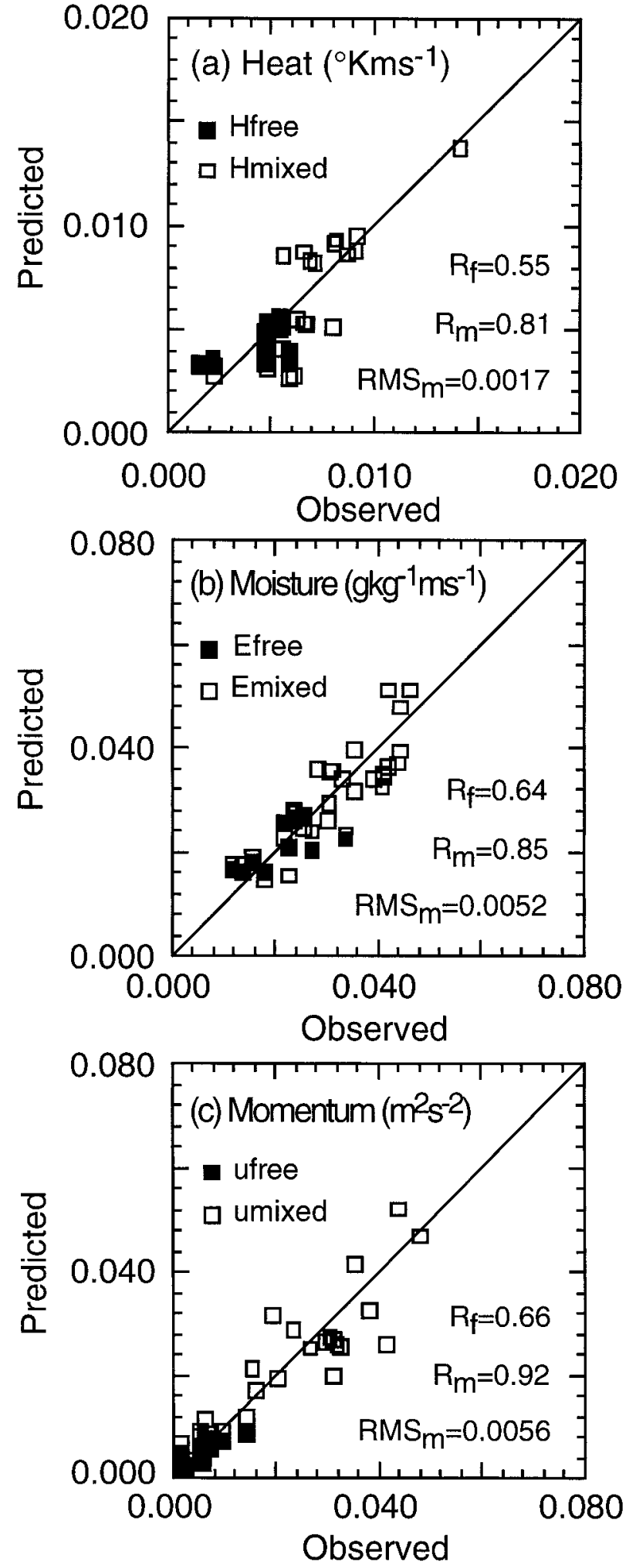

FIG. 4. Predicted and observed fluxes are compared for (a) heat, (b) moisture, and (c) momentum. Two predictions are presented: one based on free convection [(1)-(3)] with only free-convective cases plotted, and the other based on mixed convection [(13)-(15)] with all cases plotted. Coefficients determined in this study were used. of heat, moisture, and momentum. Two predictions are presented: one based on free convection [(1)-(3)] for observations with $R_{*}>3.0$, and the other based on mixed convection [(13)-(15)] for all observations. Correlation coefficients and root-mean-square differences (mixed case) between the predicted and observed values shown in Fig. 4 give an estimate of performance. The root-mean-square error differences for the sensible and latent fluxes correspond to $2 \mathrm{~W} \mathrm{~m}^{-2}$ and $16 \mathrm{~W} \mathrm{~m}^{-2}$, compared to typical magnitudes of those fluxes of 7.5 $\mathrm{W} \mathrm{m}{ }^{-2}$ and $94.3 \mathrm{~W} \mathrm{~m}^{-2}$, respectively.

Transport coefficients for the free-convective case have already been presented. The least squares best-fit coefficients for the mixed-convective case based on all the data in Tables 1 and 2 are for momentum fluxes $C_{D \mathrm{ML}}=0.00038( \pm 0.00012), b_{D \mathrm{ML}}=0.00041$ ( \pm 0.00009$)$; for sensible heat fluxes $C_{H \mathrm{ML}}=0.00044$ $( \pm 0.00005), b_{H \mathrm{ML}}=0.00030( \pm 0.00004)$; and for latent heat fluxes $C_{E \mathrm{ML}}=0.00062( \pm 0.00019), b_{E \mathrm{ML}}=$ $0.00018( \pm 0.00003)$. The error estimates were obtained by a Monte Carlo simulation (Press et al. 1986) and allowed for random errors in observed values of up to $20 \%$ of their respective means. When compared to the previously published values of $C_{D \mathrm{ML}}=0.00350$, $b_{D \mathrm{ML}} 0.00070$, and $C_{H \mathrm{ML}}=0.00100, b_{H \mathrm{ML}}=0.00025$ there are considerable differences between most of the corresponding coefficients. The marine values for the mixed momentum coefficients are similar to those for mixed heat and moisture, which is consistent with the result for the convective case with $C_{* D}$ being more nearly equal to $C_{* H}$ and $C_{* E}$ for these marine data.

Acoustic Doppler current profiler (ADCP) data from several of the ships in the IFA during the flights studied were used in an attempt to correct for the effects of surface currents on wind speed difference between the middle mixed layer and surface. These data give $0.5-\mathrm{h}$ bin-averaged values centered at approximately $20-\mathrm{m}$ depth and generally indicated eastward-moving currents with speeds up to $0.6 \mathrm{~m} \mathrm{~s}^{-1}$ but with considerable variability in space and time. These speeds and the general direction are born out by the many surface buoy trajectories plotted for December 1992 (TCIPO 1993) with the January 1993 trajectories showing more of a southward component. Since it was not possible to get an accurate estimate of the surface currents beneath each flight segment the transfer coefficients were recomputed for a $\pm 0.6 \mathrm{~m} \mathrm{~s}^{-1}$ adjustment to the wind speed.

Table 3 shows the results of these calculations. The momentum coefficient $C_{* D}$ for the free-convective case is affected most since its computation involved the low-

$\leftarrow$

Correlation coefficients $\left(R_{f}\right.$ and $R_{m}$ for the free and mixed cases) between predicted and observed values are shown. The root-meansquare error for the mixed case $\left(\mathrm{rms}_{m}\right)$ is shown. The diagonal line representing a 1:1 perfect fit is shown for reference. 
TABLE 3. Variation of CTT coefficients for a $\pm 0.6 \mathrm{~m} \mathrm{~s}^{-1}$ range of ocean surface currents, which could have affected the wind-speed difference between the mid-ML and the surface.

\begin{tabular}{lcccccc}
\hline \hline $\begin{array}{c}\text { Free convective } \\
\text { Current speed }\end{array}$ & $C^{*_{D}}$ & $C^{*}{ }_{H}$ & $C^{*}{ }_{E}$ & $b_{D}$ & $b_{H}$ & $b_{E}$ \\
\hline$+0.6 \mathrm{~m} \mathrm{~s}^{-1}$ & 0.0039 & 0.0059 & 0.0043 & 0.00029 & 0.00047 & 0.00033 \\
$\mathbf{0}$ & $\mathbf{0 . 0 0 5 3}$ & $\mathbf{0 . 0 0 6 1}$ & $\mathbf{0 . 0 0 4 4}$ & $\mathbf{0 . 0 0 0 4 1}$ & $\mathbf{0 . 0 0 0 5 0}$ & $\mathbf{0 . 0 0 0 3 5}$ \\
$-0.6 \mathrm{~m} \mathrm{~s}^{-1}$ & 0.0108 & 0.0065 & 0.0047 & 0.00081 & 0.00054 & 0.00038 \\
Mixed convective & & & & & \\
Current speed & $C_{D \mathrm{ML}}$ & $C_{H \mathrm{ML}}$ & $C_{E \mathrm{ML}}$ & $b_{D \mathrm{ML}}$ & $b_{H \mathrm{ML}}$ & $b_{E \mathrm{ML}}$ \\
\hline$+0.6 \mathrm{~m} \mathrm{~s}^{-1}$ & 0.00043 & 0.00044 & 0.00061 & 0.00026 & 0.00026 & 0.00013 \\
$\mathbf{0}$ & $\mathbf{0 . 0 0 0 3 8}$ & $\mathbf{0 . 0 0 0 4 4}$ & $\mathbf{0 . 0 0 0 6 2}$ & $\mathbf{0 . 0 0 0 4 1}$ & $\mathbf{0 . 0 0 0 3 0}$ & $\mathbf{0 . 0 0 0 1 8}$ \\
$-0.6 \mathrm{~m} \mathrm{~s}^{-1}$ & 0.00028 & 0.00043 & 0.00062 & 0.00060 & 0.00033 & 0.00023 \\
\hline
\end{tabular}

est wind speeds from $0.8-3.1 \mathrm{~m} \mathrm{~s}^{-1}$. The small changes in the heat and moisture coefficients are due to fewer or more points falling into the free-convective range. All the mixed convective case coefficients are affected since they involve wind speed, though again the momentum coefficients are most affected.

A comparison with the latest (version 2.0f) COARE bulk parameterization (Fairall et al. 1996), which was designed for light wind conditions, was also made. Figure 5 shows the comparison with correlations and rms differences between the bulk and covariance (eddy correlation) fluxes for the 25 flight segments flown at elevations of less than one-tenth of the mixed-layer thickness. At larger flux values the bulk estimates are somewhat greater than the measured covariance values. The $10-\mathrm{m}$ wind speeds for these data range from 0.8 to 7.8 $\mathrm{m} \mathrm{s}^{-1}$, so they represent a fair range of values for this region. The correlation coefficients are slightly better than those for CTT shown in Fig. 4 though the rms errors are larger. Confining the sample to cases with wind speeds of $5 \mathrm{~m} \mathrm{~s}^{-1}$ or less lowered the rms errors to $0.0017 \mathrm{~K} \mathrm{~m} \mathrm{~s}^{-1}, 0.0055 \mathrm{~g} \mathrm{~kg}^{-1} \mathrm{~m} \mathrm{~s}^{-1}$, and $0.0033 \mathrm{~m}$ $\mathrm{s}^{-1}$, respectively, for the heat, moisture, and momentum fluxes, values comparable to CTT. This is a fairly crude comparison since the aircraft was measuring at heights from $30-66 \mathrm{~m}$ and there is the possibility of some deviation from the surface values.

Using completely independent data (eddy correlation flux observations from the R/V Moana Wave), Chang and Grossman (1999) compared CTT with bulk surface flux algorithms. For their calculations $z_{i}$ was assumed to be comparable to the lifting condensation level (LCL), and mid-mixed-layer values of other variables were estimated by adjustment from observation level to the top of the surface layer $\left(\sim 0.1 z_{i}\right)$ using Monin-Obukhov similarity theory and a linear adjustment from there to the middle of the mixed layer $\left(0.5 z_{i}\right)$. Based on the Moana Wave flux observations they determined an "ocean" set of CTT coefficients and concluded that CTT was the best algorithm for calculating latent heat, sensible heat, and momentum fluxes.

The relationship between Deardorff velocity and buoyancy velocity scales given in (16) was tested. Figure 6 is a scatterplot of the two velocity scales showing the strong relationship of their magnitudes as evidenced by the least squares line passing through the origin with a slope of 1.0033 . The corresponding correlation coefficient is 0.41 with an rms error of approximately $12 \%$ of the mean. The low correlation coefficient reflects the limited range of $w_{*}$ values for these TOGA COARE flights.

Figure 7 shows a plot of buoyant versus virtual-temperature differences, which were shown to be approximately equal for convection over land. The least squares line through the origin has a slope of 0.954 , a corresponding correlation coefficient of 0.82 , and an rms error of approximately $14 \%$ of the mean. Thus, the approximation in (9) is also good for these more humid marine conditions.

A test of the prediction of $z_{i}$ given in (12) was made with the limited number of flight legs adjacent to slant vertical profiles. The predicted versus observed values of $z_{i}$ showed considerable scatter. Since the predicted value of $z_{i}$ in (12) depends on the square of the observed heat flux and on $\Delta \theta^{-2}$, and $\Delta \theta$ under marine conditions is generally quite small, there is a strong dependence on the observed heat flux and on accurate temperature measurements both at the surface and mid-mixed layer. We do not recommend use of this relationship in the COARE region. The large impact of measurement errors on reducing skill to diagnose mixed-layer depths was anticipated by Stull (1994).

\section{Conclusions}

Turbulent flux measurements made from five flights of the Electra aircraft during the TOGA COARE IOP confirmed the CTT free-convective coefficient for sensible heat flux. Averaging 12 estimates of the dimensionless mixed-layer transport coefficients gave values for $C_{* H}$ and $C_{* E}$ for heat and moisture fluxes that were not significantly different from each other and from the previously published value. However, the estimate of $C_{* D}$ from momentum fluxes is less than one-quarter of the published land-based value. There is considerable 

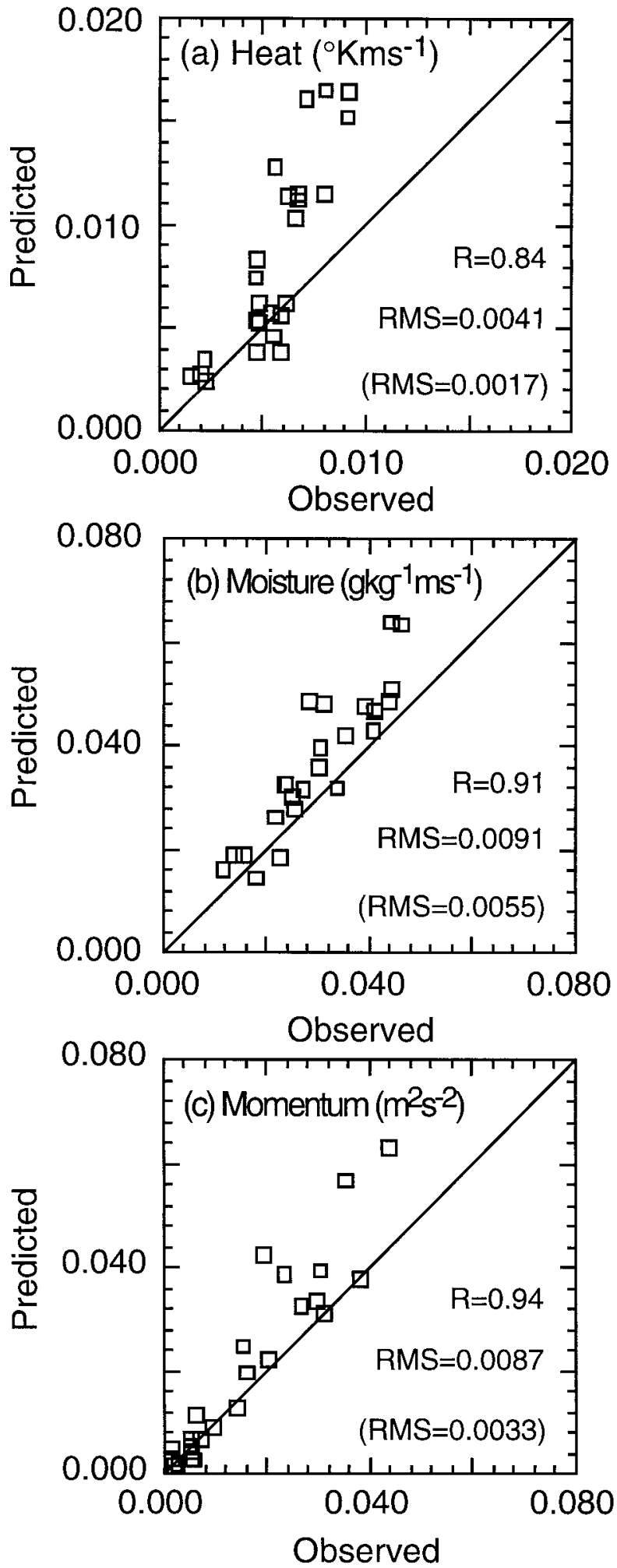

FIG. 5. Comparison of fluxes predicted by the COARE bulk parameterization vs those observed by the Electra aircraft for (a) sensible heat, (b) moisture, and (c) momentum. Correlation coefficients between predicted and observed values are shown. The root-meansquare errors are listed with the value for the cases with wind speed less than $5 \mathrm{~m} \mathrm{~s}^{-1}$ shown in parentheses. The diagonal line representing a 1:1 perfect fit is shown for reference.

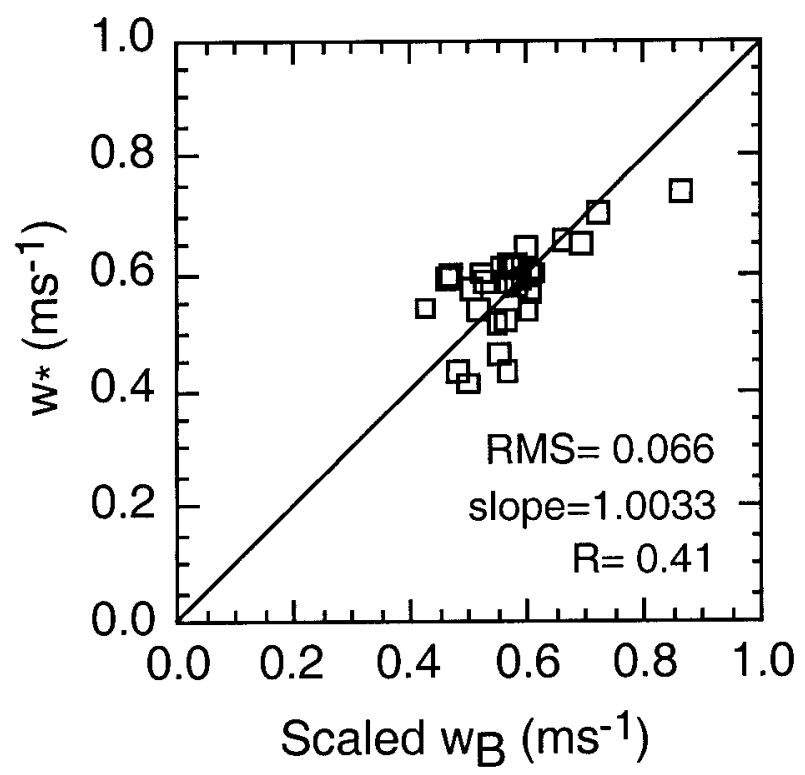

FIG. 6. Comparison of Deardorff velocity and buoyancy velocity scales described in (16). Slope of the least squares line passing through the origin, the corresponding correlation coefficient, and the root-mean-square error are shown. The diagonal line representing a $1: 1$ perfect fit is shown for reference.

scatter in the momentum data that may be due to insufficient flight-leg length used to compute the momentum fluxes, and to uncertainties in the mean mixedlayer wind speed and surface currents; but the difference is large enough to suggest that roughness-length effects or other factors need to be incorporated into the CTT.

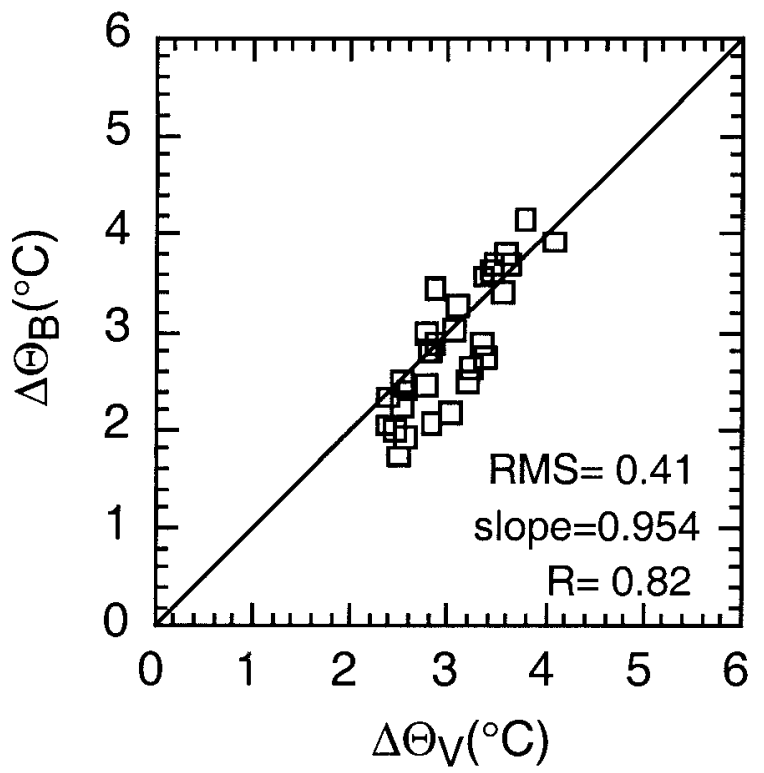

FIG. 7. Comparison of $\Delta \theta_{B}$ and $\Delta \theta_{V}$ described in (10). Slope of the least squares line passing through the origin, the corresponding correlation coefficient, and the root-mean-square error are shown. The diagonal line representing a 1:1 perfect fit is shown for reference. 
The mixed formulations of CTT, which include a wind speed factor, gave good results for heat, moisture, and momentum fluxes even under moderate wind conditions of $5-8 \mathrm{~m} \mathrm{~s}^{-1}$; however, the best-fit coefficients were considerably different than the published land-based values.

A comparison of the observed fluxes with estimates computed from the COARE bulk algorithm was made. Heat, moisture, and momentum fluxes computed using this bulk algorithm, which was designed for light wind conditions, tended to be larger than the observed fluxes for wind speeds greater than $5 \mathrm{~m} \mathrm{~s}^{-1}$. At wind speeds less than $5 \mathrm{~m} \mathrm{~s}^{-1}$ the agreement improved considerably, with rms errors comparable to those of the mixed CTT model.

Various relations resulting from the CTT were tested for marine conditions. The theoretical value of the ratio of the Deardorff velocity and buoyancy velocity scales was confirmed. The approximate equality of the buoyancy and virtual temperature differences was found to hold even in the high-humidity conditions of the equatorial Pacific. Estimation of the mixed-layer thickness from surface heat flux and temperature difference between surface and mixed-layer showed considerable scatter, thus limiting its usefulness in the tropical marine context of the COARE region.

The feasibility of extending CTT to marine conditions using the mixed formulation with adjusted coefficients has been demonstrated. Root-mean-square errors of roughly $22 \%\left(2 \mathrm{~W} \mathrm{~m}^{-2}\right.$ and $16 \mathrm{~W} \mathrm{~m}^{-2}$ for sensible and latent heat fluxes, respectively) were obtained for this mixed-convective CTT model tuned for marine conditions. More marine studies are needed to reveal the roughness and possibly other effects on CTT, and whether this model can be used in other areas of the ocean.

Acknowledgments. This work was supported mostly by National Science Foundation Grant ATM-9411467, with partial support from Canadian grants from the Atmospheric Environment Service and the Natural Sciences and Engineering Research Council. The TOGA COARE International Project Office was very helpful in providing the Electra data (processed at the NCAR ATD) and necessary documentation. Discussions with John Young, Bob Grossman, and Yolande Serra (who provided corrected radiometric SST data) are greatly appreciated. Comments from three anonymous reviewers greatly improved the manuscript.

\section{REFERENCES}

Asencio, N., J. P. Lafore, P. Pires, and J. L. Redelsperger, 1993: Analyses quotidiennes du Cepmmt durant la periode d'observations intensives de l'experience TOGA/COARE. METEO FRANCE Groupe de Meteorologie a Moyenne Echelle Note de Travail 12, 243 pp. [Available from La Librairie de Meteo-France, 2 Avenue Rapp, 75340 Paris Cedex 07 France.] Bond, G., and D. Alexander, 1994: TOGA COARE Meteorology Atlas. TOGA COARE International Project Office, $366 \mathrm{pp}$.

Chang, H.-R., and R. L. Grossman, 1999: Evaluation of bulk surface flux algorithms for light wind conditions using data from the Coupled Atmosphere-Ocean Response Experiment (COARE). Quart. J. Roy. Meteor. Soc., in press.

Fairall, C. W., E. F. Bradley, D. P. Rogers, J. B. Edson, and G. S. Young, 1996: Bulk parameterization of air-sea fluxes for Tropical Ocean-Global Atmosphere Coupled Ocean-Atmosphere Response Experiment. J. Geophys. Res., 101, 3747-3764.

Kustas, W. P., T. J. Schmugge, and L. E. Hipps, 1996: On using mixedlayer transport parameterizations with radiometric surface skin temperature for computing regional scale sensible heat flux. Bound.-Layer Meteor., 80, 205-221.

Miller, E. R., and R. B. Friesen, 1989: Standard output products from the NCAR Research Aviation Facility. NCAR Research Aviation Facility Bulletin 9, 70 pp.

Otles, Z., and J. A. Young, 1996: Influence of shallow cumuli on subcloud turbulence fluxes analyzed from aircraft data. J. Atmos. Sci., 53, 665-676.

Press, W., B. Flannery, S. Teukolsky, and W. Vetterling, 1986: Numerical Recipes. Cambridge University Press, 818 pp.

Stull, R., 1988: An Introduction to Boundary Layer Meteorology. Kluwer Academic Publishers, $666 \mathrm{pp}$.

- 1994: A convective transport theory for surface fluxes. $J$. Atmos. Sci., 51, 3-22.

- 1997: Reply. J. Atmos. Sci., 54, 579.

Sun, J., J. F. Howell, S. K. Esbensen, L. Mahrt, C. M. Greb, R. Grossman, and M. A. LeMone, 1996: Scale dependence of airsea fluxes over the western equatorial Pacific. J. Atmos. Sci., 53, 2997-3012.

TCIPO, 1992: TOGA COARE Operations Plan. TOGA COARE International Project Office, $391 \mathrm{pp}$. [Available from TCIPO UCAR, P.O. Box 3000, Boulder, CO 80307.]

— 1993: TOGA COARE Intensive Operations Period Operations Summary. TOGA COARE International Project Office, 506 pp. [Available from TCIPO UCAR, P.O. Box 3000, Boulder, CO 80307.]

TOGA COARE Flux Group, cited 1996: TOGA COARE Aircraft Offset Table. [Available online at http://www.wave.eng.uci.edu/ Projects/Toga_Cepex/togacoare.html.]

Tsukamoto, O., and H. Ishida, 1995: Turbulent flux measurements and energy budget analysis over the eqauatorial Pacific during TOGA-COARE IOP. J. Meteor. Soc. Japan, 73, 557-568.

Webster, P. J., and R. Lukas, 1992: TOGA COARE: The Coupled Ocean-Atmosphere Response Experiment. Bull. Amer. Meteor. Soc., 73, 1377-1416.

Williams, A. G., H. Kraus, and J. M. Hacker, 1996: Transport processes in the tropical warm pool boundary layer. Part I: Spectral composition of fluxes. J. Atmos. Sci., 53, 1187-1202. 